\title{
Mutant Phenotype p53 Immunohistochemical Expression Is Associated With Poor Prognostic Parameters and Disease-Free Survival in Triple- Negative Metaplastic Breast Carcinoma
}

Atif A. Hashmi ${ }^{1}$, Alina Sajid ${ }^{2}$, Muzna Hussain ${ }^{3}$, Shamail Zia ${ }^{4}$, Sabeeh Islam ${ }^{5}$, Muhammad Asad Diwan ${ }^{6}$, Syed Munqaad Ali ${ }^{7}$, Muhammad Irfan ${ }^{8}$, Farozaan Shamail ${ }^{4}$, Fazail Zia ${ }^{9}$

1. Pathology, Liaquat National Hospital and Medical College, Karachi, PAK 2. Internal Medicine, Sharif Medical and Dental College, Lahore, PAK 3. Cardiovascular Medicine, Cleveland Clinic, Cleveland, USA 4. Pathology, Ziauddin University, Karachi, PAK 5. Internal Medicine, Faisalabad Medical University, Faisalabad, PAK 6. Pathology, Aga Khan University, Karachi, PAK 7. Internal Medicine, Dow University of Health Sciences, Karachi, PAK 8. Statistics, Liaquat National Hospital and Medical College, Karachi, PAK 9. Pathology, Jinnah Sindh Medical University, Karachi, PAK

Corresponding author: Atif A. Hashmi, atifhashmi345@gmail.com

\section{Abstract}

\section{Introduction}

Metaplastic breast carcinoma (MBC) is a special type of breast cancer that is most commonly triple-negative and has the worst outcome compared to other breast tumors. $\mathrm{p} 53$ is a tumor suppressor gene that is frequently mutated in many human cancers. The association of mutant p53 immunohistochemical expression with clinical and prognostic parameters has not been widely studied in triple-negative MBC. Therefore, in this study, we evaluated the expression patterns of $\mathrm{p} 53$ in triple-negative MBC and its association with clinical and prognostic parameters.

\section{Methods}

A retrospective observational study was conducted in the Department of Histopathology at Liaquat National Hospital and Medical College, Pakistan, for a duration of 11 years. A total of 101 cases of triple-negative MBCs were included in the study. 53 immunohistochemistry was performed on the representative tissue blocks. Cases with diffuse strong positive p 53 expression were labeled mutant phenotype, while cases with weak patchy p53 expression were termed wild-type.

\section{Results}

The mean age of the patients was $48.33 \pm 11.47$ years, and the mean tumor size was $3.98 \pm 2.07 \mathrm{~cm}$. The mean Ki67 index was $48.98 \pm 22.97 \%$. The median disease-free survival of the patients was 24 (three to 68 ) months, with a median follow-up of 37 (13 to 77 ) months. Most of the cases were tumor (T)-stage II (51.5\%). Axillary metastasis was present in $36.6 \%$ of cases, with the perinodal extension in $16.8 \%$ of cases. Most cases were non-basal subtype (91.1\%), and the majority of cases were grade III (85.1\%). Recurrence was observed in $17.8 \%$ of cases. Among 101 cases, $52.5 \%$ cases showed mutant phenotype $\mathrm{p} 53$ expression. A significant association of $\mathrm{p} 53$ expression was noted with tumor grade, Ki67 index and disease-free survival. Cases with mutant phenotype $\mathrm{p} 53$ expression had a higher tumor grade, higher Ki67 index, and poorer disease-free survival than cases with wild-type p53 expression.

Hashmi et al. This is an open access article distributed under the terms of the Creative Commons Attribution License CC-BY 4.0., which permits unrestricted use, distribution, and reproduction in any medium, provided the original author and source are credited.

\section{Conclusion}

A substantial proportion of triple-negative MBC expressed diffuse strong expression (mutant phenotype) of p53 in our study, signifying a potential role of p53 as a therapeutic target in triple-negative MBC. Moreover, association of p53 with poor prognostic parameters, such as higher tumor grade and Ki67, and poor diseasefree survival underscores the prognostic significance of $\mathrm{p} 53$ in triple-negative MBC.

Categories: Pathology, General Surgery, Oncology

Keywords: metaplastic breast carcinoma, triple-negative breast carcinoma, p53, mutant phenotype, breast cancer

\section{Introduction}

Triple-negative breast cancers (TNBCs) are defined by the lack of expression of estrogen receptor (ER), progesterone receptor (PR), and human epidermal growth factor receptor 2 (HER2/neu). Compared with luminal and HER2/neu positive breast cancers, they are considered to have a poor outcome [1,2]. Metaplastic breast carcinoma $(\mathrm{MBC})$ is a special type of breast cancer that is most commonly triple-negative and thus has limited therapeutic options [3,4]. p53 is a tumor suppressor gene that is frequently mutated in many human cancers. A mutated 53 gene leads to production of a truncated protein that is indigestible inside the 


\section{Cureus}

cancer cell, and therefore remains inside the cell for a longer period. Normal human cells show weak heterogeneous expression of p53 protein by immunohistochemistry (IHC), referred to as wild-type expression. Alternatively, a mutated $\mathrm{p} 53$ gene leads to abnormal production of $\mathrm{p} 53$ protein that gives a strong and diffuse p53 expression called mutant phenotype. Previous studies have confirmed that this diffuse strong p53 expression correlates with p53 gene mutation on a molecular level [5]. Association of mutant p53 immunohistochemical expression with clinical and prognostic parameters has not been widely studied in triple-negative MBC. Therefore, in this study, we evaluated the expression patterns of p53 in triple-negative $\mathrm{MBC}$ and its association with clinical and prognostic parameters.

\section{Materials And Methods}

A retrospective observational study was conducted in the Department of Histopathology at Liaquat National Hospital and Medical College, Pakistan, for a duration of 11 years. A total of 101 cases with histopathological diagnosis of MBC, negative ER, PR and HER2/neu IHC were included in the study. Cases that received neoadjuvant chemotherapy were excluded from the study, along with cases with positive ER, PR or HER2/neu expression. Hematoxylin and eosin (H\&E)-stained slides of all cases were retrieved and diagnoses were reviewed. Moreover, ER, PR and HER2/neu immunohistochemical studies were performed to confirm the triple-negative status, as described in previous studies [6-10]. Cytokeratin 5/6 (CK5/6) was performed to subtype triple-negative MBCs into basal and non-basal subtypes. Cases with positive CK5/6 were termed as basal phenotype triple-negative MBC. Ki67 was performed to determine the proliferative index of the tumor. More than $1 \%$ nuclear expression of ER and PR in invasive cancer cells was taken as positive ER/PR expression. Moderate to strong membranous expression of HER2/neu in more than $10 \%$ invasive cancer cells was taken as positive Her2/neu expression. The average percentage of positively stained cancer cells (nuclear expression) was recorded to determine the Ki67 proliferative index. Moderate to strong cytoplasmic expression of $\mathrm{CK} 5 / 6$ was interpreted as positive expression.

p53 IHC was performed on representative tissue blocks, as described in previous studies [11-13]. Cases with diffuse strong positive $\mathrm{p} 53$ expression were labeled mutant phenotype, while cases with weak patchy p53 expression were termed wild-type (Figure 1A, 1B).

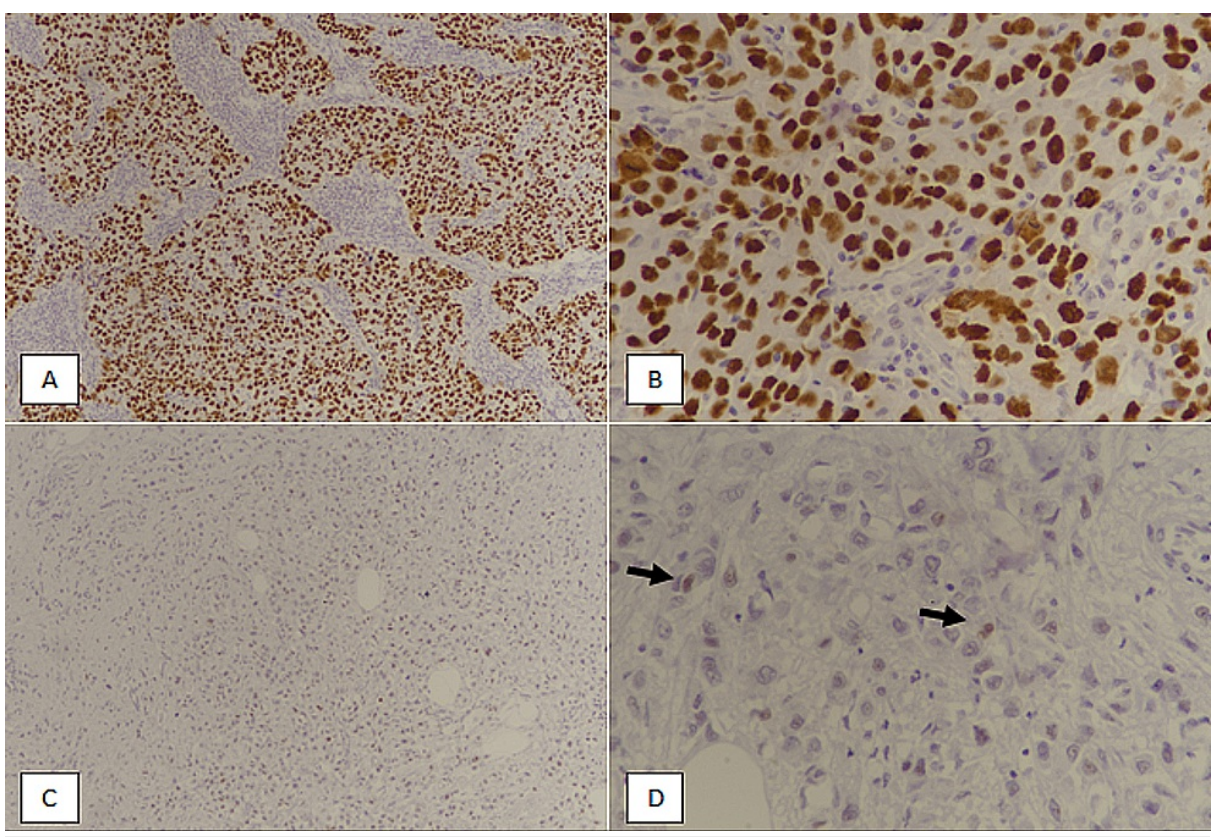

FIGURE 1: p53 expression in triple-negative metaplastic breast carcinoma. (A): IHC-staining at 100x magnification showing diffuse strong nuclear expression of p53 (mutant phenotype). (B): Mutant phenotype p53 expression at 400x magnification. (C): IHC-staining at 100x magnification depicting weak patchy p53 expression (wild-type). (D): Wild-type p53 expression at 400x magnification. Few tumor cells show weak nuclear staining (arrows).

IHC: immunohistochemical 


\section{Cureus}

independent t-test, and Fisher's exact tests were used to check the association. Survival analysis was done by the Kaplan-Meier method. P-values $<0.05$ were considered significant.

\section{Results}

The mean age of the patients was $48.33 \pm 11.47$ years and the mean tumor size was $3.98 \pm 2.07 \mathrm{~cm}$. The mean Ki67 index was $48.98 \pm 22.97 \%$. The median disease-free survival of the patients was 24 (three to 68 months), with a median follow-up of 37 (13 to 77) months. Most of the cases were tumor (T)-stage II (51.5\%). Axillary metastasis was present in $36.6 \%$ of cases, with the perinodal extension in $16.8 \%$ of cases. In situ component was present in $37.6 \%$ of cases. Lymphovascular invasion was present in $22.8 \%$ of cases. Most cases were nonbasal subtype (91.1\%), and the majority of cases were grade III (85.1\%). Recurrence was observed in $17.8 \%$ of cases. Among 101 cases, $52.5 \%$ cases showed mutant phenotype p53 expression (Table 1).

\section{Clinicopathological parameters}

Age (years), mean $\pm S D$

Tumor size $(\mathrm{cm})$, mean \pm SD

Ki67 index (\%), mean \pm SD

Disease-free survival (months), median (range)

T-stage

T1, n (\%)

T2, n (\%)

T3, n (\%)

Axillary metastasis

Present, $\mathbf{n}(\%)$

Absent, $\mathrm{n}(\%)$

$\mathrm{N}$-stage

No, n (\%)

N1, n (\%)

N2, n (\%)

N3, n (\%)

Perinodal extension

Present, n (\%)

Absent, $\mathrm{n}(\%)$

84 (83.2)

Necrosis

Absent, $\mathrm{n}(\%)$

Focal, $\mathrm{n}(\%)$

59 (58.4)

Extensive, n (\%)

27 (26.7)

Fibrosis

Mild, n (\%)

$26(25.7)$

Moderate, n (\%)

57 (56.4)

Severe, $n(\%)$

$18(17.8)$

Lymphocytic infiltration

Absent, $\mathrm{n}(\%)$

Focal, $\mathrm{n}(\%)$

78 (77.2)

Extensive, $\mathrm{n}(\%)$
14 (13.9) 


\section{Cureus}

Insitu component

Present, n (\%)

Absent, n (\%)

Lymphovascular invasion

Present, n (\%)

Absent, n (\%)

Dermal lymphatic invasion

Present, n (\%)

Absent, n (\%)

Pagetoid spread

Present, n (\%)

Absent, n (\%)

99 (98)

Triple-negative subtype

Basal, n (\%)

Non-basal, n (\%)

Chemotherapy

Yes, n (\%)

Radiation

Yes, n (\%)

\section{Tumor grade}

Grade II, n (\%)

Grade III, n (\%)

Survival status

Alive, n (\%)

Recurrence

Yes, n (\%)

p53

Wild phenotype, n (\%)

\section{TABLE 1: Clinicopathological features of studied population}

$\mathrm{SD}$, standard deviation; T, tumor; N, nodal

Table 2 shows the association of p53 expression with clinicopathological parameters. A significant association of p53 expression was noted with tumor grade, Ki67 index and disease-free survival. Cases with mutant p53 phenotype had a higher tumor grade, higher Ki67 index, and poorer disease-free survival than cases with wild-type p53 expression. Alternatively, no significant association of p53 expression was noted 


\section{Cureus}

with age, tumor size, T-stage, $\mathrm{N}$-stage and triple-negative subtype. 


\section{Cureus}

\begin{tabular}{|c|c|c|c|}
\hline \multirow{3}{*}{ Clinicopathological parameters } & \multicolumn{2}{|l|}{ Values } & \multirow{3}{*}{ P-value } \\
\hline & \multicolumn{2}{|l|}{ p53 expression } & \\
\hline & Wild Phenotype & Mutant Phenotype & \\
\hline Age (years), mean $\pm S D^{*}$ & $49.25 \pm 11.22$ & $47.49 \pm 11.74$ & 0.444 \\
\hline Tumor size $(\mathrm{cm})$, mean $\pm \mathrm{SD}^{\star}$ & $4.33 \pm 2.22$ & $3.66 \pm 1.89$ & 0.109 \\
\hline Ki67 index (\%), mean \pm SD* $^{*}$ & $44.17 \pm 22.41$ & $53.34 \pm 22.80$ & $0.044^{\star \star \star \star}$ \\
\hline Disease-free survival (months), mean $\pm \mathrm{SD}^{\star}$ & $33.15 \pm 15.08$ & $20.45 \pm 6.93$ & $<0.0001^{\star \star \star \star \star}$ \\
\hline \multicolumn{4}{|l|}{ T-stage ${ }^{\star \star}$} \\
\hline T1, n (\%) & $7(14.6)$ & $13(24.5)$ & \multirow{3}{*}{0.139} \\
\hline T2, n (\%) & $23(47.9)$ & $29(54.7)$ & \\
\hline T3, n (\%) & $18(37.5)$ & $11(20.8)$ & \\
\hline \multicolumn{4}{|l|}{ Axillary metastasis ${ }^{\star \star}$} \\
\hline Present, n (\%) & $18(37.5)$ & $19(35.8)$ & \multirow{3}{*}{0.863} \\
\hline Absent, $n(\%)$ & $30(62.5)$ & $34(64.2)$ & \\
\hline \multicolumn{3}{|l|}{ N-stage $e^{\star \star \star}$} & \\
\hline N0, n (\%) & $30(62.5)$ & $34(64.2)$ & \multirow{4}{*}{0.337} \\
\hline N1, n (\%) & $12(25)$ & $8(15.1)$ & \\
\hline N2, n (\%) & $1(2.1)$ & $5(9.4)$ & \\
\hline N3, n (\%) & $5(10.4)$ & $6(11.3)$ & \\
\hline \multicolumn{4}{|l|}{ Perinodal extension ${ }^{\star \star}$} \\
\hline Present, n (\%) & $6(12.5)$ & $11(20.8)$ & \multirow{2}{*}{0.268} \\
\hline Absent, n (\%) & $42(87.5)$ & $42(79.2)$ & \\
\hline \multicolumn{4}{|l|}{ Triple-negative subtype $e^{\star \star \star}$} \\
\hline Basal, n (\%) & $3(6.3)$ & $6(11.3)$ & \multirow{2}{*}{0.493} \\
\hline Non-basal, n (\%) & 45 (93.8) & $47(88.7)$ & \\
\hline \multicolumn{4}{|l|}{ Tumor grade ${ }^{\star \star}$} \\
\hline Grade II, n (\%) & $11(22.9)$ & $4(7.5)$ & \multirow{2}{*}{$0.030^{\star \star \star \star}$} \\
\hline Grade III, n (\%) & 37 (77.1) & $49(92.5)$ & \\
\hline \multicolumn{4}{|l|}{ Survival status ${ }^{\star *}$} \\
\hline Alive, n (\%) & $43(89.6)$ & 39 (73.6) & \multirow{2}{*}{$0.040^{\star \star \star *}$} \\
\hline Expired, n (\%) & $5(10.4)$ & $14(26.4)$ & \\
\hline \multicolumn{4}{|l|}{ Recurrence ${ }^{\star \star}$} \\
\hline Yes, n (\%) & $8(16.7)$ & 10 (18.9) & \multirow{2}{*}{0.773} \\
\hline No, n (\%) & $40(83.3)$ & $43(81.1)$ & \\
\hline
\end{tabular}

\section{TABLE 2: Association of clinicopathological features with p53 expression}

${ }^{\star}$ Independent t-test was applied, ${ }^{\star \star}$ Chi-square test was applied, ${ }^{\star \star \star}$ Fisher’s exact test was applied, ${ }^{\star \star \star \star}$ Significant as $<0.05$

SD, standard deviation; T, tumor; N, nodal 
Figure 2 shows the association of p53 expression with disease-free survival by Kaplan-Meier analysis. A significant association of $\mathrm{p} 53$ expression was noted with disease-free survival. Poor disease-free survival was noted in cases with mutant p53 phenotype.

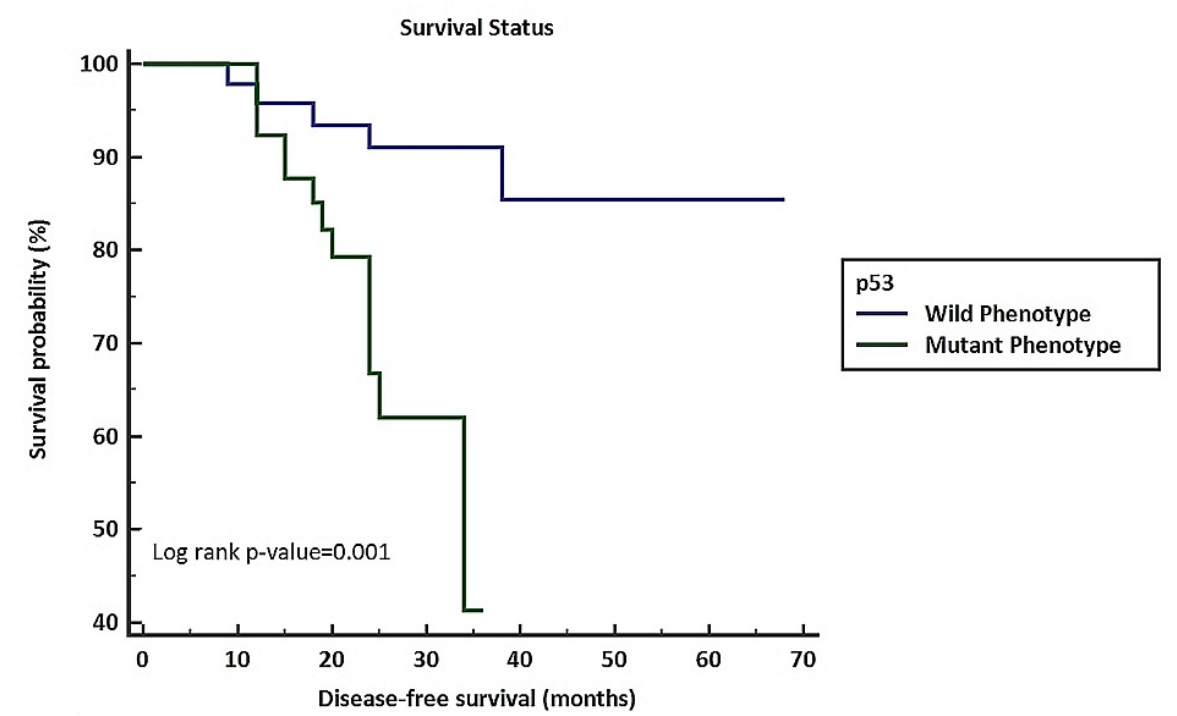

\section{Number at risk \\ Group: Wild Phenotype

\begin{tabular}{|c|c|c|c|c|c|c|c|}
\hline 48 & 46 & 40 & 25 & 13 & 6 & 1 & 0 \\
\hline \multicolumn{8}{|c|}{ Group: Mutant Phenotype } \\
\hline 53 & 52 & 22 & 4 & 0 & 0 & 0 & 0 \\
\hline
\end{tabular} \\ FIGURE 2: Association of $\mathrm{p} 53$ expression with disease-free survival by Kaplan-Meier method}

\section{Discussion}

In this study, we found that a significant percentage of cases of triple-negative $\mathrm{MBC}$ had mutant phenotype p53 expression. Moreover, mutant phenotype $\mathrm{p} 53$ expression was significantly associated with poor prognostic parameters such as higher tumor grade and higher mean Ki67 index. Furthermore, mutant phenotype $\mathrm{p} 53$ expression was associated with shorter disease-free survival, thus suggesting a prognostic value of $\mathrm{p} 53$ in triple-negative $\mathrm{MBC}$.

MBCs are characterized by a carcinomatous component (CC) that can be in situ or invasive, along with a heterogeneous sarcomatous component (HSC). Lien et al. investigated p53 mutation patterns in both CC and HSC of MBCs and identified identical p53 mutations in both components, suggesting a monoclonal histogenesis of both components. Furthermore, based on the patterns of $\mathrm{p} 53$ mutations, they concluded that p53 mutation is an early event in MBC, before the invasion, and it is sustained throughout the tumor progression [14].

Li et al., in a study involving a cohort of 278 cases of TNBC, identified p53 immunoexpression in $58.6 \%$ of cases. Concordant with our findings, they also found a significant association of $\mathrm{p} 53$ expression with worse overall survival and poor disease-free survival [15]. Yang et al. also found that p53 positivity was predictive of outcome in breast cancer patients with visceral metastasis [16].

We found $52.5 \%$ positivity for $\mathrm{p} 53$ protein (mutant phenotype) in triple-negative MBC. Comparable frequencies of $\mathrm{p} 53$ expression were found in other studies $[15,16]$. Duffy et al. discussed the potential role of various compounds that can reactivate mutant $\mathrm{p} 53$ protein and convert it to acquire wild-type properties, thus signifying mutant $\mathrm{p} 53$ as a potential therapeutic target [17]. Similarly, Synnott et al. identified an antip53 drug targeting mutant p53 in TNBC [18].

Our study has a few limitations, such as not performing molecular studies to identify p53 mutations. Moreover, single-institution data further limit the value of the study. However, our findings signify a prognostic value for $\mathrm{p} 53$ expression in triple-negative MBC.

\section{Conclusions}

We found p53 IHC to be of prognostic value in triple-negative MBC, owing to the significant association of 
mutant phenotype p53 expression with higher tumor grade and Ki67 index, and poorer disease-free survival. Furthermore, as a significant proportion of triple-negative MBC had mutant phenotype p53 expression, p53 may serve as a potential therapeutic target. However, large-scale prospective cohort studies are recommended to evaluate its significance as a therapeutic biomarker. Moreover, molecular correlation of immunohistochemical p53 expression is also needed with p53 gene mutations.

\section{Additional Information \\ Disclosures}

Human subjects: Consent was obtained or waived by all participants in this study. N/A issued approval N/A. Not needed for retrospective studies. . Animal subjects: All authors have confirmed that this study did not involve animal subjects or tissue. Conflicts of interest: In compliance with the ICMJE uniform disclosure form, all authors declare the following: Payment/services info: All authors have declared that no financial support was received from any organization for the submitted work. Financial relationships: All authors have declared that they have no financial relationships at present or within the previous three years with any organizations that might have an interest in the submitted work. Other relationships: All authors have declared that there are no other relationships or activities that could appear to have influenced the submitted work.

\section{References}

1. Hashmi AA, Naz S, Hashmi SK, et al.: Epidermal growth factor receptor (EGFR) overexpression in triplenegative breast cancer: association with clinicopathologic features and prognostic parameters. Surg Exp Pathol. 2019, 2:6.

2. Hashmi AA, Edhi MM, Naqvi H, Faridi N, Khurshid A, Khan M: Clinicopathologic features of triple negative breast cancers: an experience from Pakistan. Diagn Pathol. 2014, 9:43. 10.1186/1746-1596-9-43

3. Hashmi AA, Aijaz S, Mahboob R, et al.: Clinicopathologic features of invasive metaplastic and micropapillary breast carcinoma: comparison with invasive ductal carcinoma of breast. BMC Res Notes. 2018, 11:531. 10.1186/s13104-018-3623-z

4. Haroon S, Zia S, Shirazi UA, et al.: Metaplastic breast carcinoma: clinicopathological parameters and prognostic profile. Cureus. 2021, 13:e14347. 10.7759/cureus.14347

5. Murnyák B, Hortobágyi T: Immunohistochemical correlates of TP53 somatic mutations in cancer. Oncotarget. 2016, 7:64910-2. 10.18632/oncotarget.11912

6. Hashmi AA, Munawar S, Rehman N, et al.: Invasive papillary carcinoma of the breast: clinicopathological features and hormone receptor profile. Cureus. 2021, 13:e13480. 10.7759/cureus.13480

7. Hashmi AA, Zia S, Yaqeen SR, et al.: Mucinous breast carcinoma: clinicopathological comparison with invasive ductal carcinoma. Cureus. 2021, 13:e13650. 10.7759/cureus.13650

8. Munawar S, Haider R, Ali S, et al.: Triple-negative metaplastic breast carcinoma: association of epidermal growth factor receptor expression with prognostic parameters and clinical outcome. Cureus. 2021, 13:e15006. 10.7759/cureus.15006

9. Hashmi AA, Iftikhar SN, Munawar S, Shah A, Irfan M, Ali J: Encapsulated papillary carcinoma of breast: clinicopathological features and prognostic parameters. Cureus. 2020, 12:e11282. 10.7759/cureus.11282

10. Hashmi AA, Iftikhar SN, Haider R, Haider R, Irfan M, Ali J: Solid papillary carcinoma of breast: clinicopathologic comparison with conventional ductal carcinoma of breast. Cureus. 2020, 12:e11172. 10.7759/cureus.11172

11. Mumtaz S, Hashmi AA, Hasan SH, Edhi MM, Khan M: Diagnostic utility of p53 and CK20 immunohistochemical expression grading urothelial malignancies. Int Arch Med. 2014, 7:36. 10.1186/17557682-7-36

12. Hashmi AA, Naz S, Hashmi SK, et al.: Prognostic significance of p16 \& p53 immunohistochemical expression in triple negative breast cancer. BMC Clin Pathol. 2018, 18:9. 10.1186/s12907-018-0077-0

13. Hashmi AA, Hussain ZF, Hashmi SK, et al.: Immunohistochemical over expression of p53 in head and neck squamous cell carcinoma: clinical and prognostic significance. BMC Res Notes. 2018, 11:433. 10.1186/s13104-018-3547-7

14. Lien HC, Lin CW, Mao TL, Kuo SH, Hsiao CH, Huang CS: p53 overexpression and mutation in metaplastic carcinoma of the breast: genetic evidence for a monoclonal origin of both the carcinomatous and the heterogeneous sarcomatous components. J Pathol. 2004, 204:131-9. 10.1002/path.1624

15. Li JP, Zhang XM, Zhang Z, Zheng LH, Jindal S, Liu YJ: Association of p53 expression with poor prognosis in patients with triple-negative breast invasive ductal carcinoma. Medicine (Baltimore). 2019, 98:e15449. 10.1097/MD.0000000000015449

16. Yang P, Du CW, Kwan M, Liang SX, Zhang GJ: The impact of $\mathrm{p} 53$ in predicting clinical outcome of breast cancer patients with visceral metastasis. Sci Rep. 2013, 3:2246. 10.1038/srep02246

17. Duffy MJ, Synnott NC, Crown J: Mutant p53 in breast cancer: potential as a therapeutic target and biomarker. Breast Cancer Res Treat. 2018, 170:213-9. 10.1007/s10549-018-4753-7

18. Synnott NC, Bauer MR, Madden S, et al.: Mutant p53 as a therapeutic target for the treatment of triplenegative breast cancer: preclinical investigation with the anti-p53 drug, PK11007. Cancer Lett. 2018, 414:99-106. 10.1016/j.canlet.2017.09.053 